\title{
Understanding coping strategies during pregnancy and the postpartum period: a qualitative study of women living with HIV in rural Uganda
}

Scholastic Ashaba ${ }^{1 *}$, Angela Kaida², Bridget Frances Burns ${ }^{3}$, Kasey O'Neil ${ }^{3}$, Emma Dunkley ${ }^{2}$, Christina Psaros ${ }^{4,5}$, Jasmine Kastner ${ }^{6}$, Alexander C. Tsai ${ }^{4,5}$, David R. Bangsberg ${ }^{3,5}$ and Lynn T. Matthews ${ }^{3,7}$

\begin{abstract}
Background: In sub-Saharan Africa, 58\% of adults living with HIV are women. In Uganda, HIV prevalence is 8.3\% for women compared to $6.1 \%$ for men. Access to antiretroviral therapy (ART) and prevention of mother to child transmission (PMTCT) programs have enabled women living with HIV (WLWH) to have children with minimal risk of perinatal transmission. Nevertheless, pregnant WLWH face many challenges. We explored women's perceptions of how they cope with the challenges of pregnancy and the postpartum period as HIV-infected women.

Methods: We conducted semi-structured interviews with postpartum WLWH accessing ART who had a pregnancy within 2 years prior to recruitment between February-August, 2014. Childbearing associated stressors and coping strategies were discussed. We used content analysis to identify major themes and NVivo 10 software facilitated data analysis.

Results: Twenty women were interviewed with median age 33 (IQR: 28-35) years, CD4 cell count 677 cells/mm $\mathrm{mm}^{3}$ (IQR: 440-767), number of live births 4 (IQR: 2-6), and number of living children 3 (IQR: 2-4.3). We summarize five identified coping strategies within a socio-ecological framework according to Bronfenbrenner's Ecological Model. Coping strategies on the individual level included acceptance of self and HIV status, and self-reliance. On the interpersonal level, participants reported coping through support from partners, family, and friends. On the organizational level, participants reported coping through HIV-related healthcare delivery and system supports. At the community level, women reported coping through support from church and spirituality.

Conclusions: The results highlight coping strategies used by WLWH to manage the myriad challenges faced during pregnancy and the postpartum period. Intervention programs for WLWH must emphasize psychosocial care and incorporate strategies that address psychosocial challenges in the HIV care package in order to optimize well-being. Additionally policies that support networks of WLWH should be put in place and funding support should be provided through existing funding mechanisms in order to respond to the needs and challenges of WLWH. Programmes that support WLWH for economic empowerment and improved livelihoods should be strengthened across all regions in the country.
\end{abstract}

Keywords: Women, HIV, Pregnancy, Postpartum, Coping strategies, Rural Uganda

\footnotetext{
*Correspondence: sashaba@must.ac.ug; ashaba.schola@gmail.com

'Department of Psychiatry, Mbarara University of Science and Technology,

Mbarara, Uganda

Full list of author information is available at the end of the article
} 


\section{Background}

Worldwide, HIV disproportionately affects women and in sub-Saharan Africa 58\% of adults living with HIV are women [1]. The adult prevalence of HIV in Uganda is $7.3 \%$ overall; $8.3 \%$ for women compared to $6.1 \%$ among men [2]. Access to antiretroviral therapy (ART) and prevention of mother to child transmission (PMTCT) programs enable women living with HIV (WLWH) to have children with minimal risks to their health and perinatal transmission [3]. However, being HIV positive and pregnant remains a challenging experience for women $[4,5]$

Pregnant WLWH experience psychosocial challenges during pregnancy and childbirth including emotional distress and fear of perinatal transmission [6, 7], stigma [8] lack of social support [9-11] , food insecurity [12] and poverty $[7,13]$, challenges related to disclosure of HIV status [14-19] , violence [20-22], and concerns about their own physical health and survival. These stressors increase women's vulnerability and psychological distress which can further compromise their pregnancy and postpartum experience [23-26] and lead to a range of emotional and psychological problems including postpartum depression [22, 27-29].

Despite the myriad of challenges experienced by WLWH there is limited data exploring how women in resource poor settings cope with the challenges. Yet a strong relationship between coping and psychological wellbeing among people living with chronic illnesses including HIV has been reported [30]. According to Lazarus and Folkman [31], coping is a process that mediates the relationship between experiences and outcomes of psychological stress. In the process of coping, individuals use both cognitive and behavioral strategies to manage stressful situations. Coping helps individuals to manage emotional distress and the problems that cause psychological distress. Coping strategies used by individuals to manage emotional distress are known as emotion-focused coping strategies while those used by individuals to manage situations causing distress are known as problem-focused coping strategies [31]. Previous research shows that people living with HIV who employ positive coping can realize positive psychosocial and physical health outcomes including fewer physical symptoms, enhanced quality of life, less psychological distress, and higher self-esteem [32-36].

Active coping involves behavioural and cognitive efforts to actively confront the stressful situation and challenges using strategies like problem-solving, changing the mind set and seeking relevant information [25]. In addition, social support and coping may influence outcomes of chronic illnesses through promoting medication adherence [33, 37]. Positive strategies for coping help individuals manage emotional stress while also helping them to manage problems that cause psychological distress [31] .

In a previous Uganda AIDS Rural Treatment Outcome (UARTO) cohort study of women living with HIV accessing ART, we observed a high pregnancy incidence of 9.4/100 person years of follow-up, with nearly one-third of women becoming pregnant within 3 years of ART initiation [38]. In this cohort, $39 \%$ of women were depressed, with higher depression scores among pregnant and postpartum women [39]. While the rollout of Option $\mathrm{B}+$ and other strategies to reduce perinatal transmission are important in supporting women to meet their reproductive goals and have uninfected children [40], supporting women's mental and emotional health is also crucial to growing healthy families, communities, and populations. Understanding how WLWH cope with the challenges associated with pregnancy and the postpartum period is key to the development of effective interventions that can minimize psychological distress and support healthy pregnancy and postpartum outcomes. Using qualitative data from a study exploring experiences of depression among pregnant WLWH engaged in care, this paper explores women's descriptions of how they cope with the challenges of pregnancy and postpartum period.

\section{Methods}

\section{Study setting}

We conducted this study in Mbarara, a rural town in Southwestern Uganda located approximately $270 \mathrm{~km}$ from Kampala, the capital city. Mbarara town has an estimated population of 195,013 people [41]. Adult HIV prevalence in the region is estimated at $10 \%$, with women carrying a higher burden of infection [42] with a reported prevalence of $12 \%$ among women attending antenatal clinic in Mbarara hospital [42, 43] . All study participants were accessing care at a public HIV clinic within the regional referral hospital. The clinic offers comprehensive HIV care, including ART, free of charge to patients.

\section{Study participants and recruitment}

Study participants were WLWH recruited from the Uganda AIDS Rural Treatment Outcomes (UARTO) cohort [43]. From 2005-2015, UARTO followed over $700 \mathrm{HIV}$-infected men and women of at least 18 years of age, on ART, receiving care at the local HIV clinic, and living within $60 \mathrm{~km}$ of the clinic site. Eligible participants for this qualitative sub-study were females, enrolled in the parent UARTO study; and experienced a pregnancy in the 2 years prior to recruitment. The primary aim was to explore experiences of depression among WLWH during pregnancy and postpartum. We used stratified random sampling to select eligible participants with a 
range of depression experiences based on their responses to the Hopkins Symptoms Checklist (HSCL-16) within the parent cohort study.

During a previous UARTO study visit, women were screened for depression symptom severity using a modified version of the HSCL-15 for depression. Based on previous studies using HSCL in Uganda, a 16th item was included: "Feeling like I don't care about my health" [44]. Each of the 16 symptoms is scored on a 4-item Likert scale ranging from not at all (1), a little (2), quite a bit (3), to extremely (4), and the total depression severity score was calculated as the mean of the 16 items, with higher scores indicating greater depression symptom severity. The HSCL has been used to assess depression in general population samples and among people living with HIV in sub-Saharan African settings, with good reliability and contrast validity [45]. We considered a dichotomous measure of "probable depression", defined as an HSCL-16 score $>1.75$, which has been previously used as a positive screen for depression in the UARTO cohort study and other sites [39, 44, 46, 47].

We selected women with 4 response patterns on the Hopkins Symptoms Checklist (HSCL) scores collected in quarterly visits prior to, during, and after the referent pregnancy: (1) HSCL scores falling below 1.75 postpartum; (2) HSCL rising above 1.75 postpartum; (3) stably high $(\geq 1.75)$ HSCL scores; and (4) stably low $(<1.75)$ HSCL scores. Trained research assistants (RAs) contacted potential participants by phone, explained the purpose of the study, the benefits, and the risks of participating. If interested, the Research assistant (RA) scheduled an interview at a location and time chosen by the participant and the informed consent process took place on the interview day, ensuring voluntary participation, confidentiality and safety.

\section{Data collection}

We conducted semi-structured interviews with twenty participants from February through August 2014 using a structured interview guide. Point of saturation was reached for our primary research question of women's experiences of depression during the postpartum period. We developed the interview guide based on the literature of postpartum depression with input from both local and international experts with experience in reproductive and mental health. We used guidelines articulated by Huberman and Miles [48]. We piloted the interview guide with study staff, and colleagues to assess its clarity and content, and revised accordingly. We translated and back-translated the guide to ensure consistency.

Interviews lasted approximately one hour and explored women's experiences during pregnancy and postpartum periods. The interview guide explored symptoms of depression and the effect on the pregnancy and postpartum experience of HIV positive women, participants' thoughts and feelings about becoming pregnant, how their HIV status influenced their thoughts and feelings towards pregnancy, and their partner's thoughts towards the referent pregnancy. The final section of the interview explored feelings and experiences of the participants following childbirth (see Additional file 1). The interview guide was piloted extensively prior to use. After piloting, some of the questions in the interview guide were dropped and others rephrased to improve clarity. Ugandan RAs trained in qualitative research methods and fluent in English and the local language conducted the interviews and were blinded to participants' quantitative depression scores and patterns.

\section{Ethical considerations}

All participants provided voluntary written informed consent at study enrollment. The Institutional Review Committee, Mbarara University of Science and Technology; the Partners Human Research Committee, Massachusetts General Hospital; and the Research Ethics Board of Simon Fraser University approved the study. We received clearance for conducting our study from the Uganda National Council for Science and Technology and from the Research Secretariat in the Office of the President.

A Ugandan psychiatrist (SA) trained research assistants to recognize signs and symptoms of depression. If the RAs noticed signs or symptoms of acute and severe distress, they were instructed to refer the participant to the Mental Health Clinic. Two participants used our referral protocol over the course of the study. RAs were intentionally blinded to the depression scores of the participants.

\section{Data analysis}

Demographic information for each participant was collected from the UARTO cohort database. RAs translated and transcribed audio recordings of the interviews into English. Transcripts were reviewed by separate RAs and a psychiatrist (SA) to assess translation quality and fidelity. All research team members reviewed and discussed transcripts and developed a codebook (see Additional file 2) through an iterative process. The codebook guided the coding process, which was completed by two members of the research team. After coding a subset of four interviews, the two coders compared coding for four interviews to ensure coding reliability and to verify understanding of the codebook (Kappa statistic $=0.82$ ) [49] after which they coded the rest of the interviews independently. After coding all interviews, the research team further discussed the emergent themes in the context 
of coding. We used thematic analysis to identify major themes and NVivo 10 software facilitated data analysis.

\section{Results}

Forty-two participants were eligible to participate in the study and 20 were recruited, including 4 with falling HSCL scores postpartum, 6 with rising HSCL scores postpartum, 3 with stably high HSCL scores, and 7 with stably low HSCL scores. We aimed to recruit a similar number of participants in each category, however only 5 of 42 eligible participants had stably high HSCL scores.

Participants had a median age of 33 years (range 22 to 40 ) and $95 \%$ had achieved plasma HIV-RNA suppression. Women had a median of 3 living children and a median CD4 cell count of 677 cells $/ \mathrm{mm}^{3}$ (Table 1).

\section{Challenges and coping}

Women in our study described several challenges to being a pregnant HIV-positive woman, including lack of financial means to secure adequate food, shelter, and clothing; lack of support for financial and emotional needs; difficulties adhering to ART and navigating PMTCT guidelines; and internalized HIV-related stigma. In the face of tremendous challenges, the coping strategies that women employed to manage hardships were discussed.

We summarize the five identified coping strategies within a more general socio-ecological framework [50]. On the individual level, coping strategies included (1) acceptance of self and HIV status, and (2) self-reliance. On the interpersonal level, participants reported coping through (3) financial, emotional, and social support from partners, family, and friends. On the organizational level, participants reported coping through (4) HIV-related healthcare delivery and system supports. On the community level, women reported gleaning (5) support from the church community and spirituality.

We discuss each of these five themes with a view to informing interventions to support pregnant and postpartum WLWH to overcome psychosocial challenges.

Table 1 Socio-demographic characteristics of women living with HIV with pregnancy within 2 years prior to interview $(n=20)$

\begin{tabular}{ll}
\hline Characteristic & Median [IQR] \\
\hline Age (years) & $33[28,35]$ \\
Time on ART (years) & $2.3[1.8,5.1]$ \\
Number of live births & $4[2,6]$ \\
Number of living children & $3[2,4]$ \\
Months between pregnancy outcome & $15[7,21]$ \\
and interview & \\
Most recent CD4 cell count (cells $\left./ \mathrm{mm}^{3}\right)$ & $677[440,767]$ \\
\hline
\end{tabular}

(1) Individual level: Acceptance of HIV serostatus and self Participants expressed profound HIV-related internal stigma, which led to self-isolation and compromised engagement in HIV-related care during pregnancy. As this participant vividly describes:

In my life, I was feeling I hated myself; I was suspicious that everybody knew my HIV status. I felt I was finished, I did not want to see people, and I spent much of the time in the house. Whenever I would see someone, I would think that this one knows things about me, I was always quiet and alone. I would not be outside, unless when I was going to hospital. (Participant \#8, 5 months postpartum).

However, the process of viewing HIV as an infection that affects many people and accepting her own HIV status was a powerful step towards self-acceptance. She continues:

I denied myself, but later I consoled myself and I felt I would go through this. I consoled myself as a person and said that let me not become a laughing stock, good enough am not the first one and am not the last one [to have HIV] . It is a usual thing; let me accept. (Participant \#8).

Another participant explained that starting ART initiated her process of accepting her HIV status and herself, underscoring the importance of self-acceptance as a fundamental step towards coping with the challenges of being a pregnant WLWH.

Before I started ARVs, I was not well, physically, and my CD4s were low. I would feel rejected among my friends. However when I started ARVs I felt strong, and I said 'why don't I have a baby?' I had good health, I came to like myself, I cooked food, I ate it, and I was happy. I was not thinking that HIV is even there. I accepted myself. I felt like HIV was like any other illness like malaria or just a minor accident you can get while taking a walk. I felt that strong. (participant \#6 8 months postpartum).

(2) Individual level: Self-reliance Several participants described experiences of partners denying responsibility for the pregnancy and abandoning the relationship. Without financial support from partners, participants explained how they relied on their own skills and assets to provide for themselves and their babies. The following participant explains how difficult her relationship with her partner was and what she went through to provide for herself and the baby. 
There is no good relationship with my partner because he has a second wife. When he saw that the children were dying, he said ...let me bring another wife, the children you will have could also die. Therefore, he brought another wife and she has two children... This time when I told him that I was pregnant, he did not mind at first but when I was 8 months, he said, it is not mine; you know where you will put it [the baby]. I said, ok no problem; I will cater for myself...I felt my heart telling me, after all, I know how to work for myself, I must look for how to survive, look for money to make sure that after delivery I get food to eat. I ran up and down, did day labor, got money, kept it, bought my things for carrying the baby, I prepared myself and packed until I got into labor and came to hospital.- (Participant \#11, 12 months postpartum)

Another participant whose partner did not want her to have more children because of her HIV status recounted the experience of her partner denying the pregnancy and his responsibility to care for her and their child. She then describes how she coped through self-reliance and a confidence in her own abilities.

When I told him [about the pregnancy], he [partner] quarrelled, and he kept quarrelling, but later ... he was like of course you know how you are [HIV+]; you would stop there [having children]. You do it again [get pregnant] you will be damaging your life. Don't think that [I] am stopping you from having children but you should know what you are. Now when I saw that he was going to stress me (... they keep, teaching us here [clinic] that when you stress yourself you lose CD4 and you will be reducing on your life), I gave up on him as a person. I knew I would not be stranded like failing to get what to put on, what to eat or what to clothe the baby; I was not scared about those because I knew I would find them. Whether the job is there or not, can a person insist and remain on one thing forever? If I lost the job, I would look for something else to do. I have my two hands.(Participant \#5, 5 months postpartum)

(3) Interpersonal level: Support from partners, families, and friends

Some participants described that receiving support from their partners and other family members positively impacted their pregnancy experience and postpartum outcomes. This participant described how her partner committed to helping her adhere to ART and PMTCT protocols so they could have an HIV-uninfected baby.

He (partner) was not OK [with the pregnancy] initially, though he wanted to have a child, he was also scared like me, and he was even scared more.... in the end he decided that we should not abort the baby... He promised that he would be helping me, reminding me, go to the clinic and take my medications, to make sure that I follow all these steps and see what will come out. He did more than me (laughs) because even bringing the child to the clinic, he is the one who decided and kept on monitoring, is he taking medicine, are you taking him to the clinic, can I have a look at the papers, he was more serious than I was. - (Participant \#4 woman, 6 months postpartum).

Some of the participants relied on family members and friends for financial support to take care of themselves and their children. This woman discusses how friends and family members provided financial and other forms of tangible support.

When I gave birth, they [community members] helped me a lot, people gave me food, and I did not suffer at all. Even the 20,000 [Ugandan shillings] I had kept, I bought clothes for the baby. Now am fine, I have no problem. I get support from people, some give me clothes, such things, when am stuck with no school fees and transport to hospital, they help me with the money and I pay them later .... I do not get stressed; I befriended those who love me. Those who help me are also sick [HIV+], so we know each other in such problems. In addition, my sister and my brother also help me. (Participant \#12 woman, 9 months postpartum)

Support from friends, especially those also living with HIV, helped women identify hope within their pregnancy experience.

I first felt bad and asked why I was going to give birth to those to leave behind [after death]. However, I have a friend I talked to; she has been on medicine [ARVs] for long. She told me, "You want to tell me that all these people you see...You can even produce 8 children, when you are still alive, the children will grow and get married when you are there [alive]. Don't lose hope" that is how I gave up on thoughts and worries. - (Participant \#15, 20 months postpartum).

(4) Organizational level: HIV-related healthcare delivery and system supports

For some women, the support of trusted healthcare providers regarding PMTCT practice helped women overcome fears of perinatal transmission, engage in HIV care, and have an HIV-uninfected child.

After realizing that my second child was the way I am [HIV-positive], I felt that I should try to have another 
child. ... I was scared but at the same time, I wanted to have one [HIV-negative child]. ... I wanted a child, so I decided to accept and follow whatever the health care providers told me and make sure I get a child who is free [HIV negative]. Therefore, I decided not to stress myself ... You know after accepting, there was nothing much, because I made sure I took my medicine, came for antenatal care, and things were normal. (Participant \#4 woman, 6 months postpartum).

Observing other women at the HIV treatment clinic who had successful pregnancies helped women to find strength to cope with the fears and challenges of their own pregnancy.

I got so many problems... Because they tested me and found that I was HIV positive, I asked myself, 'will I deliver the baby and it survives or am I going to suffer with this pregnancy or die?' However, when I kept getting UARTO staff [HIV clinic] comforting me and telling me to take my medicine properly I got hope. Whenever I would go to hospital and see other women with their children who are healthy [HIV negative] yet they are on medication, I became strong. I stopped thinking and worrying, I was as if I had no virus, I ate and drank and I became strong. - (Participant \#20, 18 months postpartum.

(5) Community level: Support from church community and spirituality

Support from the church community and personal religious beliefs and spirituality helped some women manage challenges. This participant shared her experience of how she had considered suicide on several occasions but started a process of recovery with support from prayer and her church community.

I was thinking a lot, I would think about this pregnancy, "Oh my God why did I do it, [get pregnant]" and then I would curse the man. I woke up one morning I went to throw myself in the river, [but] when I saw how the water was moving, I walked back home. I was thinking, the man had left me, I did not have money, I am HIV positive and I did not have anyone to turn to. Later I said, "Let me be patient, God will take care of me". So whenever I would feel bothered, I would pray and I said let me hand myself to God. It helped me, because if I had not become born again [religion], I would have killed the baby and myself. However, whenever I would go to church, and I see how they pray and preach I would feel touched. I saw myself getting better and I saw that God could work. (Participant \#8, 5 months postpartum)
Another participant had misunderstandings with the partner who wanted to take the child away from her following their separation but she noted that she coped through prayer and the support of her church community and in the end, managed to stay with her child.

Before I got pregnant, we had no problem at all. However, after giving birth, he behaved extremely badly towards me. ... He disturbed me a lot to the point that he no longer wanted me to work. He refused to provide support for the child and wanted to take her [child] to the other wife. He [partner] gave me many troubles. I would say that this man has killed me [infected her with HIV] and now he is making me suffer. I prayed the rosary and dedicated myself to the Virgin Mary to help me through these troubles and God helped me through. I would ask people in the village to pray for me so that my child is not taken away from me. I offered all that to God, he helped me through, in the end I was allowed to stay with my child. - (Participant \#19, 21 months postpartum).

\section{Discussion}

Our study highlights positive coping strategies WLWH employed to manage challenges encountered during pregnancy and postpartum period in a rural African setting. The findings suggest that with positive coping strategies women WLWH manage extreme social and psychological challenges and have positive pregnancy outcomes.

Consistent with previous studies, we found that acceptance of HIV status and acceptance of self was a primary coping strategy used by women. Acceptance of HIV status and acceptance of self helps individuals to reframe their situation $[51,52]$ and is also a sign of motivation to deal with difficult situations, overcome denial and face reality [53].

Our study findings showed that some participants who had limited support from their partners became selfreliant to provide for themselves and their child. This finding is consistent with previous work showing that economic stability helps women with HIV to cope positively and overcome HIV-related stressors [54, 55]. Although women are able to cope and are important actors, they should not be saddled with all the responsibility. Partners, community members, family members and health care providers, and a larger structural environment should also play a role in alleviation of the challenges. After all, the role of partner and family and community support has been documented to reduce the risk of psychological distress among WLWH $[9-11,56]$. In addition to helping WLWH cope, social support enables women to gain useful information about their 
health and availability of health care services [57-60]. Importantly, social support has been shown to protect against HIV disease progression $[10,11,61]$ leading to longer survival among persons with HIV [62].

Some of our participants reported that support from partners and other family members helped them navigate pregnancy-related aspects of HIV including ART adherence. However as documented by Udobong and colleagues [63] partners are not always supportive and many tend to blame the women for having brought HIV to the family and abandon them.

Some women relied on family members for tangible and intangible support to cope with the stressors of being pregnant and living with HIV. These findings are in line with previous research highlighting that family support is associated with reduced stress, improved medication adherence, and reduced risks of psychological distress leading to improved quality of life among HIV positive women [52, 63-66]. Moreover, studies have shown that family support improves physical outcomes and protects against negative social consequences of living with HIV $[9,10]$. This finding differs from what was found in Nigeria where WLWH reported that they were often abandoned by their families after disclosing their HIV status and this limited their access to medical care and led to disease progression [63].

Our findings also indicated that support from healthcare providers regarding PMTCT practice helped women overcome fears of perinatal transmission, engage in HIV care, and thus have HIV-uninfected children. This is in agreement with a previous study in Uganda where women attending PMTCT clinics described health workers as being caring and supportive, which helped women to deal with challenges and fears related to an HIV positive diagnosis [67].

Participants were able to cope and gained strength by observing other women who had gone through similar experiences. This is related to what has been documented in a previous study that knowing someone who is living with HIV enables those infected to accept their HIV status because of the inner comfort they feel knowing that someone shares their experience $[25,68]$. This finding echoes earlier work showing that peer support groups play an important role in helping women living with HIV to understand HIV and PMTCT programs leading to retention in care and adherence to ART [69-72]. On the other hand participants in our study did not feel comfortable disclosing their status to community members for fear of stigma and ridicule contrary to what has been reported in a previous study that community members play a role in helping WLWH adhere to their medication and cope with the illness [70].

Some of our participants leaned on involvement with the church, spirituality, and prayer to cope with the stressors of pregnancy and the postpartum. This finding is consistent with previous research that religious involvement is common among HIV positive pregnant women and has been noted to be an important factor for adherence to medication and engagement in PMTCT care [52, 54, 73, 74]. In a South African study among people recently diagnosed with HIV, Myint [51] showed that religious involvement helped individuals find new meaning in life, obtain spiritual support, and cope with the psychosocial effects of an HIV diagnosis. Use of religion as a coping strategy has also been reported in previous studies to be an important source of strength and meaning to life for women living with HIV $[34,51,52]$.

A previous study in Uganda revealed spirituality to be an important strategy for WLWH to cope with HIVrelated stigma, with women expressing that while they were often stigmatized in the general community, a belief in "God's acceptance" empowered them to persevere and find hope for the future [75]. Consistent with previous studies, we similarly found that religious involvement and prayer played an important role in helping WLWH cope with the challenges of pregnancy and the postpartum period [76-79]. Our findings differ from findings by Trevino and colleagues [34] who noted that spiritual struggle affects the ability of HIV positive individuals to cope with their illness.

The study had limitations that included a small study sample that may limit generalizability of the study findings to all HIV positive women during pregnancy and the postpartum period. Secondly, we interviewed women with pregnancy in the previous 2 years, which meant most of the women had navigated the pregnancy and the postpartum period and had adapted ways to cope with the challenges associated with pregnancy. The findings may also be limited by recall bias since we interviewed women about their pregnancy and postpartum experiences several months after childbirth a fact that could have had an effect on the recollection of their experiences of pregnancy and childbirth. We also did not do our analysis by depression scores given the small sample size and the fact that coping strategies were not something we explored in our interview. Finally, participants that were enrolled in UARTO received quarterly follow-up care, with reimbursement for transportation and as such, they may not be a typical representation of women living with HIV and engaged in HIV care.

\section{Conclusions}

Despite availability of ART and PMTCT care, HIV positive pregnant and postpartum women face numerous psychosocial challenges that are not addressed in HIV or antenatal clinics. Community- and clinic-based programs for WLWH must acknowledge the myriad psychosocial stressors acting on the health and well-being of pregnant 
and post-partum women and incorporate psychosocial care within their care programming. Although WLWH are able to cope with challenges there is a need to encourage WLWH to form support groups through which they can encourage each other as they navigate HIV care. Moreover, previous research has documented that WLWH who are in peer support groups adhere to the HIV treatment cascade which improves physical and emotional outcomes [68-70]. Health care providers serving pregnant WLWH may help minimize psychosocial challenges and psychological distress by working to support, promote, and facilitate positive strategies for coping that women are already using. These efforts include regular screening of patients for psychological distress in the HIV clinics and refer for mental health assessment and treatment.

Community education and sharing information on how different WLWH cope with challenges may be beneficial to other women who are grappling with similar challenges.

Additionally policies that support networks of WLWH should be put in place and funding support should be provided through existing funding mechanisms in order to respond to the needs and challenges of WLWH. Local support networks in Mbarara like The AIDS Support Organisation (TASO) and other programmes that support WLWH for economic empowerment and improved livelihoods should be strengthened. Finally networks that aim to support WLWH including The AIDS Support organisation (TASO), International community of WLWH and AIDS in Eastern Africa (ICWEA), MAMA's CLUB which is a psychosocial support group for HIV positive mothers, the National coalition of women with AIDS in Uganda and Global Coalition of Women against AIDS in Uganda should be strengthened and supported to expand across all HIV clinics to benefit all WLWH.

\section{Additional files}

Additional file 1: Interview guide: Postpartum and antenatal depression among women enrolled in Uganda AIDS Rural Treatment Outcomes Study (UARTO): Patient Participant Interview Guide. (DOCX 26 kb)

Additional file 2: Codebook: Postpartum Depression (PPD) Participant Interviews Codebook. (DOCX 30 kb)

\section{Abbreviations}

ART: Antiretroviral therapy; HIV: Human immunodeficiency virus; HSCL: Hopkins Symptom Checklist; PMTCT: Prevention of mother-to-child transmission of HIV; UARTO: Uganda AIDS Rural Treatment Outcomes; WLWH: Women living with HIV

\section{Acknowledgments}

We would like to express our appreciation to the women who participated in this study and the research team for their invaluable contributions. In a special way we acknowledge Magdalena Robak who contributed greatly to the development of standard operating procedures that guided the development of our interview guide, participant eligibility, recruitment, and consent and interview process.

\section{Funding}

This study was supported in part by U.S. National Institutes of Health R21 HD069194, K23 MH095655, R01 MH054907, P30 Al027763, U01 CA066529, K24 MH87227, K23 MH099916 and R01MH087328; and the Sullivan Family Foundation.The authors additionally acknowledge salary support through U.S. National Institutes of Health D43TW010128 (S.A.).

\section{Availability of data and materials}

The datasets supporting the conclusions of this article are included within the article as quotes from the transcripts and additional files including the codebook and interview guide are attached. The coding tree and interview guide are attached as supplementary materials. Information from the participants' transcripts can be shared on request by contacting the corresponding author.

\section{Authors' contributions}

SA, participated in the development of the interview guide supervised the data collection process, reviewed transcripts, took part in data interpretation and wrote the first draft of the manuscript. AK and LTM conceived the idea and designed the study, developed interview guides, monitored the data collection process and were very instrument in data analysis and interpretation of the results and manuscript writing. CP was part of data analysis and interpretation and manuscript writing. EM, BFB and $\mathrm{KO}$ coded the data, participated in data analysis and interpretation and contributed to the manuscript writing. JK coordinated the study from the start to the end, contributed to the data collection methods, development of the interview guide, review of the transcripts and supervision of data collection and contributed greatly to the methods section of the manuscript. ACT and DRB were PIs of the parent cohort study and contributed during the preparation of the manuscript and reviewed the final draft before a decision to submit was reached. All authors reviewed and approved the final manuscript.

\section{Competing interests}

All authors declare that they have no conflict of interest.

\section{Consent for publication}

The manuscript does not include any individual personal data of the participants.

\section{Ethics approval and consent to participate}

We received ethics approval from the Institutional Review Committee, Mbarara University of Science and Technology; the Partners Human Research Committee, Massachusetts General Hospital; and the Research Ethics Board of Simon Fraser University. We received clearance for conducting our study from the Uganda National Council for Science and Technology and from the Research Secretariat in the Office of the President of Uganda. All participants provided voluntary written informed consent at study enrollment.

\section{Publisher's Note}

Springer Nature remains neutral with regard to jurisdictional claims in published maps and institutional affiliations.

\section{Author details}

'Department of Psychiatry, Mbarara University of Science and Technology, Mbarara, Uganda. ${ }^{2}$ Faculty of Health Sciences, Simon Fraser University, Burnaby, Canada. ${ }^{3} \mathrm{MGH}$ Global Health, Massachusetts General Hospital, Boston, MA, USA. ${ }^{4}$ Department of Psychiatry, Massachusetts General Hospital, Boston, MA, USA. ${ }^{5}$ Harvard Medical School, Boston, MA, USA. ${ }^{6}$ Research Institute McGill University Health Centre Montreal, Montreal, Canada. ${ }^{7}$ Division of Infectious Diseases, Department of Medicine, Massachusetts General Hospital, Boston, MA, USA.

Received: 3 May 2016 Accepted: 3 May 2017

Published online: 08 May 2017

\section{References}

1. UNAIDS: progress report on the global plan towards the elimination of new HIV infections among children by 2015 and keeping their mothers alive. Geneva: UNAIDS; 2013.

2. UNAIDS. The Gap report. Geneva: UNAIDS; 2014

3. Bannink-Mbazzi F, Lowicki-Zucca M, Ojom L, Kabasomi SV, Esiru G, Homsy J. High PMTCT program uptake and coverage of mothers, their partners, and babies in northern Uganda: achievements and lessons 
learned over 10 years of implementation (2002-2011). J Acquir Immune Defic Syndr. 2013;62(5):e138-45.

4. Scorgie F, Blaauw D, Dooms T, Coovadia A, Black V, Chersich M. "I get hungry all the time": experiences of poverty and pregnancy in an urban healthcare setting in South Africa. Glob Health. 2015;11(1):1.

5. Kastner J, Matthews LT, Flavia N, Bajunirwe F, Erikson S, Berry NS, Kaida A: Antiretroviral therapy helps HIV-positive women navigate social expectations for and clinical recommendations against childbearing in Uganda. AIDS Res Treat 2014, 2014.

6. Lazarus R, Struthers H, Violari A. Hopes, fears, knowledge and misunderstandings: responses of HIV-positive mothers to early knowledge of the status of their baby. AIDS Care. 2009;21(3):329-34.

7. Kapetanovic S, Dass-Brailsford P, Nora D, Talisman N. Mental health of HIV-seropositive women during pregnancy and postpartum period: a comprehensive literature review. AIDS Behav. 2014;18(6):1152-73.

8. Kavanaugh ML, Moore AM, Akinyemi O, Adewole I, Dzekedzeke K, Awolude O, Arulogun $\mathrm{O}$. Community attitudes towards childbearing and abortion among HIV-positive women in Nigeria and Zambia. Cult Health Sex. 2013;15(2):160-74.

9. Blaney NT, Fernandez MI, Ethier KA, Wilson TE, Walter E, Koenig LJ, Group PGEP. Psychosocial and behavioral correlates of depression among HIVinfected pregnant women. AIDS Patient Care STDS. 2004;18(7):405-15.

10. Ashton E, Vosvick M, Chesney M, Gore-Felton C, Koopman C, O'Shea K, Maldonado J, Bachmann MH, Israelski D, Flamm J. Social support and maladaptive coping as predictors of the change in physical health symptoms among persons living with HIV/AIDS. AIDS Patient Care STDs. 2005;19(9):587-98.

11. Leserman J, Petitto JM, Golden RN, Gaynes BN, Gu H, Perkins DO, Silva SG, Folds JD, Evans DL. Impact of stressful life events, depression, social support, coping, and cortisol on progression to AIDS. Am J Psychiatry. 2000;157(8):1221-8.

12. Tsai AC, Tomlinson M, Comulada WS, Rotheram-Borus MJ. Food insufficiency, depression, and the modifying role of social support: evidence from a population-based, prospective cohort of pregnant women in peri-urban south Africa. Soc Sci Med. 2016;151:69-77.

13. Beauliere A, Toure S, Alexandre PK, Kone K, Pouhe A, Kouadio B, Journy N, Son J, Ettiegne-Traore V, Dabis F, et al. The financial burden of morbidity in HIV-infected adults on antiretroviral therapy in Cote d'Ivoire. Plos One. 2010; 5(6):e11213.

14. Kapetanovic S, Christensen S, Karim R, Lin F, Mack WJ, Operskalski E, Frederick T, Spencer L, Stek A, Kramer F. Correlates of perinatal depression in HIV-infected women. AIDS Patient Care STDS. 2009;23(2):101-8.

15. Bennetts A, Shaffer N, Manopaiboon C, Chaiyakul P, Siriwasin W, Mock P, Klumthanom K, Sorapipatana S, Yuvasevee C, Jalanchavanapate S. Determinants of depression and HIV-related worry among HIV-positive women who have recently given birth, Bangkok, Thailand. Soc Sci Med. 1999;49(6):737-49.

16. Cuca YP, Onono M, Bukusi E, Turan JM. Factors associated with pregnant women's anticipations and experiences of HIV-related stigma in rural Kenya. AIDS Care. 2012;24(9):1173-80.

17. Myer L, Morroni C, Cooper D. Community attitudes towards sexual activity and childbearing by HIV-positive people in South Africa. AIDS Care. 2006; 18(7):772-6.

18. Makin JD, Forsyth BW, Visser MJ, Sikkema KJ, Neufeld S, Jeffery B. Factors affecting disclosure in South African HIV-positive pregnant women. AIDS Patient Care STDS. 2008:22(11):907-16.

19. Visser MJ, Neufeld S, De Villiers A, Makin JD, Forsyth BW. To tell or not to tell: South African women's disclosure of HIV status during pregnancy. AIDS Care. 2008;20(9):1138-45

20. Ceccon RF, Meneghel SN. [HIV and violence against women: study in a municipality with high prevalence of Aids in the South of Brazil]. Rev Panam Salud Publica. 2015;37(4-5):287-92.

21. Olowookere SA, Fawole OI, Adekanle DA, Adeleke NA, Abioye-Kuteyi EA. Patterns and Correlates of Intimate Partner Violence to Women Living With HIV/AIDS in Osogbo, Southwest Nigeria. Violence Against Women. 2015; 21(11):1330-40.

22. Tsai AC, Tomlinson M, Comulada WS, Rotheram-Borus MJ. Intimate Partner Violence and Depression Symptom Severity among South African Women during Pregnancy and Postpartum: Population-Based Prospective Cohort Study. Plos Med. 2016;13(1):e1001943.

23. Kinyanda E, Hoskins S, Nakku J, Nawaz S, Patel V. Prevalence and risk factors of major depressive disorder in HIV/AIDS as seen in semi-urban Entebbe district, Uganda. BMC Psychiatry. 2011;11(1):205.
24. Morrow K, Costello T, Boland R. Understanding the psychosocial needs of HIV-positive women: a qualitative study. Psychosomatics. 2001;42(6):497-503.

25. Kotzé M, Visser M, Makin J, Sikkema K, Forsyth B. Psychosocial variables associated with coping of HIV-positive women diagnosed during pregnancy. AIDS Behav. 2013;17(2):498-507.

26. Brouwer C, Lok C, Wolffers I, Sebagalls S. Psychosocial and economic aspects of HIV/AIDS and counselling of caretakers of HIV-infected children in Uganda. AIDS Care. 2000;12(5):535-40.

27. Turan B, Stringer KL, Onono M, Bukusi EA, Weiser SD, Cohen CR, Turan JM. Linkage to HIV care, postpartum depression, and HIV-related stigma in newly diagnosed pregnant women living with HIV in Kenya: a longitudinal observational study. BMC Pregnancy Childbirth. 2014;14(1):400.

28. Peltzer K, Shikwane M. Prevalence of postnatal depression and associated factors among HIV-positive women in primary care in Nkangala district, South Africa. S Afr J HIV Med. 2011;12(4):24-8.

29. Dewing S, Tomlinson M, le Roux IM, Chopra M, Tsai AC. Food insecurity and its association with co-occurring postnatal depression, hazardous drinking, and suicidality among women in peri-urban South Africa. J Affect Disord. 2013;150(2):460-5.

30. Kraaij V, van der Veek SM, Garnefski N, Schroevers M, Witlox R, Maes S. Coping, goal adjustment, and psychological well-being in HIV-infected men who have sex with men. AIDS Patient Care STDS. 2008;22(5):395-402.

31. Lazarus RS, Folkman S. Stress, appraisal, and coping. New York: Springer Publishing Company; 1984

32. Mcintosh RC, Rosselli M. Stress and coping in women living with HIV: a meta-analytic review. AIDS Behav. 2012;16(8):2144-59.

33. Vyavaharkar M, Moneyham L, Tavakoli A, Phillips KD, Murdaugh C, Jackson K, Meding G. Social support, coping, and medication adherence among HIVpositive women with depression living in rural areas of the southeastern United States. AIDS Patient Care STDS. 2007;21(9):667-80.

34. Trevino KM, Pargament Kl, Cotton S, Leonard AC, Hahn J, Caprini-Faigin CA, Tsevat J. Religious coping and physiological, psychological, social, and spiritual outcomes in patients with HIV/AIDS: cross-sectional and longitudinal findings. AIDS Behav. 2010;14(2):379-89.

35. Stein JA, Rotheram-Borust M-J. Cross-sectional and longitudinal associations in coping strategies and physical health outcomes among HIV-positive youth. Psychol Health. 2004;19(3):321-36.

36. Chida Y, Vedhara K. Adverse psychosocial factors predict poorer prognosis in HIV disease: a meta-analytic review of prospective investigations. Brain Behav Immun. 2009;23(4):434-45.

37. Katz IT, Ryu AE, Onuegbu AG, Psaros C, Weiser SD, Bangsberg DR, Tsai AC. Impact of HIV-related stigma on treatment adherence: systematic review and meta-synthesis. J Int AIDS Soc. 2013;16(3 Suppl 2):18640.

38. Kaida A, Matthews LT, Kanters S, Kabakyenga J, Muzoora C, Mocello AR, Martin JN, Hunt P, Haberer J, Hogg RS. Incidence and predictors of pregnancy among a cohort of HIV-positive women initiating antiretroviral therapy in Mbarara, Uganda. Plos One. 2013;8(5):e63411.

39. Kaida A, Matthews LT, Tsai AC, Kanters S, Robak M, Psaros C, Kabakyenga J, Boum Y, Haberer JE, Martin JN. Depression during pregnancy and the postpartum among HIV-infected women on antiretroviral therapy in Uganda. J Acquir Immune Defic Syndr (1999). 2014;67 Suppl 4:S179.

40. Ahmed S, Kim MH, Abrams EJ. Risks and benefits of lifelong antiretroviral treatment for pregnant and breastfeeding women: a review of the evidence for the Option B+ approach. Curr Opin HIV AIDS. 2013;8(5):474-89.

41. UBOS: The population of the regions of the Republic of Uganda and all cities and towns of more than 15,000 inhabitants. Kamapala: Citypopulation. de Quoting Uganda Bureau of Statistics (UBOS); 2014.

42. Uganda MOH. The Uganda AIDS Indicator Survey UAIS. Kampala; 2012.

43. Jeffrey Campbell BB, Sylvia Natukinda, Nir Eyal, Angella Musiimenta, Jessica Haberer: Social Support Through Observational Trial Participation Among HIV Patients in Southwest Uganda. 10th International Conference on HIV Treatment and Prevention Adherence Miami, FL June 29th 2015.

44. Bolton P, Ndogoni L. Cross-cultural assessment of trauma-related mental illness (Phase II). World Vision Uganda and the Johns Hopkins University. Assessment of Mnetal Health Impact of Transitional population. 2001.

45. Tsai AC, Bangsberg DR, Frongillo EA, Hunt PW, Muzoora C, Martin JN, Weiser SD: Food insecurity, depression and the modifying role of social support among people living with HIV/AIDS in rural Uganda. Soc Sci Med 2012, 74(12).

46. Derogatis LR, Lipman RS, Rickels K, Uhlenhuth EH, Covi L. The Hopkins Symptom Checklist (HSCL): a self-report symptom inventory. Behav Sci. 1974;19(1):1-15. 
47. Martinez P, Andia I, Emenyonu N, Hahn JA, Hauff E, Pepper L, Bangsberg DR. Alcohol use, depressive symptoms and the receipt of antiretroviral therapy in southwest Uganda. AIDS Behav. 2008;12(4):605-12.

48. Huberman M, Miles MB. The qualitative researcher's companion. Thousand Oaks: Sage; 2002.

49. Landis JR, Koch GG. The measurement of observer agreement for categorical data. Biometrics. 1977;33(1):159-74.

50. Brofenbrenner U. The ecology of human development. Am Psychol. 1979; 32:513-31.

51. Myint T, Mash B. Coping strategies and social support after receiving HIVpositive results at a South African district hospital. SAMJ. 2008;98(4):276-7.

52. Kotzé M, Visser M, et al. "The coping strategies used over a two-year period by HIV-positive women who had been diagnosed during pregnancy." AIDS care. 2013;25(6):695-701.

53. Lutgendorf SK, Antoni MH, Ironson G, Starr K, Costello N, Zuckerman M, Klimas N, Fletcher MA, Schneiderman N. Changes in cognitive coping skills and social support during cognitive behavioral stress management intervention and distress outcomes in symptomatic human immunodeficiency virus (HIV)-seropositive gay men. Psychosom Med. 1998; 60(2):204-14.

54. de Faria ER, Gonçalves TR, de Carvalho FT, Lopes RCS, Piccinini CA. Coping Strategies Among Brazilian Pregnant Women Living With HIV1. Paidéia. 2014;24(57):67-74

55. Kim J, Pronyk P, Barnett T, Watts C. Exploring the role of economic empowerment in HIV prevention. AIDS. 2008;22:S57-71.

56. Natamba BK, Mehta S, Achan J, Stoltzfus RJ, Griffiths JK, Young SL: The association between food insecurity and depressive symptoms severity among pregnant women differs by social support category: a crosssectional study. Matern Child Nutr 2016

57. Leslie MB, Stein JA, Rotheram-Borus MJ. The impact of coping strategies, personal relationships, and emotional distress on health-related outcomes of parents living with HIV or AIDS. J Soc Pers Relat. 2002;19(1):45-66.

58. Ware NC, Idoko J, Kaaya S, Biraro IA, Wyatt MA, Agbaji O, Chalamilla G, Bangsberg DR. Explaining adherence success in sub-Saharan Africa: an ethnographic study. Plos Med. 2009;6(1):e11

59. Rouhani SA, O'Laughlin KN, Faustin ZM, Tsai AC, Kasozi J, Ware NC: The role of social support on HIV testing and treatment adherence: A qualitative study of HIV-infected refugees in southwestern Uganda. Glob Public Health 2016:1-14.

60. Ware NC, Pisarski EE, Haberer JE, Wyatt MA, Tumwesigye E, Baeten JM, Celum CL, Bangsberg DR. Lay social resources for support of adherence to antiretroviral prophylaxis for HIV prevention among serodiscordant couples in sub-Saharan Africa: a qualitative study. AIDS Behav. 2015;19(5):811-20.

61. Leserman J, Jackson ED, Petitto JM, Golden RN, Silva SG, Perkins DO, Cai J, Folds JD, Evans DL. Progression to AIDS: the effects of stress, depressive symptoms, and social support. Psychosom Med. 1999;61(3):397-406.

62. Patterson TL, Shaw WS, Semple SJ, Cherner M, McCutchan JA, Atkinson JH Grant I, Nannis E, Group HNRC. Relationship of psychosocial factors to HIV disease progression. Ann Behav Med. 1996;18(1):30-9.

63. Udobong RUN, Charles $\mathrm{O}$, Adat P, Udonwa R. Coping strategy of women with HIV-AIDS: influence of care-giving, family social attitude, and effective communication. Science. 2015;3(1):107-13.

64. Nguyen TA, Oosterhoff $P$, Ngoc YP, Wright $P$, Hardon A. Self-help groups can improve utilization of postnatal care by HIV-infected mothers. J Assoc Nurses AIDS Care. 2009;20(2):141-52.

65. Sanders LB. Women's voices: the lived experience of pregnancy and motherhood after diagnosis with HIV. J Assoc Nurses AIDS Care. 2008;19(1):47-57.

66. Olley BO. Psychological distress in the first year after diagnosis of HIV infection among women in South Africa. Afr J AIDS Res. 2006:5(3):207-15.

67. Rujumba J, Neema S, Tumwine JK, Tylleskar T, Heggenhougen HK. Pregnant women's experiences of routine counselling and testing for HIV in Eastern Uganda: a qualitative study. BMC Health Serv Res. 2013;13:189.

68. Visser M, Mundell J, De Villiers A, Sikkema K, Jeffery B. Development of structured support groups for HIV-positive women in South Africa. SAHARA J. 2006;2(3):333-43

69. Rotheram-Borus MJ, Richter L, Van Rooyen H, van Heerden A, Tomlinson M, Stein A, Rochat T, de Kadt J, Mtungwa N, Mkhize L, et al. Project Masihambisane: a cluster randomised controlled trial with peer mentors to improve outcomes for pregnant mothers living with HIV. Trials. 2011;12:2.

70. Namukwaya Z, Barlow-Mosha L, Mudiope P, Kekitiinwa A, Matovu JN, Musingye E, Ssebaggala JN, Nakyanzi T, Abwooli JJ, Mirembe D, et al. Use of peers, community lay persons and village health team (VHT) members improves 6-week postnatal clinic (PNC) follow-up and early infant HIV diagnosis (EID) in urban and rural health units in Uganda: a 1-year implementation study. BMC Health Serv Res. 2015;15(1):555.

71. Sam-Agudu NA, Cornelius LJ, Okundaye JN, Adeyemi OA, Isah HO, Wiwa OM, Adejuyigbe E, Galadanci H, Afe AJ, Jolaoso I, et al. The impact of mentor mother programs on PMTCT service uptake and retention-in-care at primary health care facilities in Nigeria: a prospective cohort study (MoMent Nigeria). J Acquir Immune Defic Syndr. 2014;67 Suppl 2:S132-8.

72. Murithi LK, Masho SW, Vanderbilt AA. Factors enhancing utilization of and adherence to prevention of mother-to-child transmission (PMTCT) service in an urban setting in Kenya. AIDS Behav. 2015;19(4):645-54.

73. Rocha N, Fleck M. Evaluation of quality of life and importance given to spirituality/religiousness/personal beliefs (SRPB) in adults with and without chronic health conditions. Revista De Psiquiatria Clínica. 2011:38(1):19-23.

74. Maman S, Cathcart R, Burkhardt G, Omba S, Behets F. The role of religion in HIV-positive women's disclosure experiences and coping strategies in Kinshasa, Democratic Republic of Congo. Soc Sci Med. 2009;68(5):965-70.

75. Hodge DR, Roby JL. Sub-Saharan African women living with HIV/AIDS: an exploration of general and spiritual coping strategies. Soc Work. 2010;55(1):27-37.

76. Cotton S, Puchalski CM, Sherman SN, Mrus JM, Peterman AH, Feinberg J, Pargament Kl, Justice AC, Leonard AC, Tsevat J. Spirituality and religion in patients with HIV/AIDS. J Gen Intern Med. 2006;21(S5):S5-S13.

77. Yi MS, Mrus JM, Wade TJ, Ho ML, Hornung RW, Cotton S, Peterman AH, Puchalski CM, Tsevat J. Religion, spirituality, and depressive symptoms in patients with HIV/AIDS. J Gen Intern Med. 2006;21(S5):S21-7.

78. Dalmida SG. Spirituality, mental health, physical health, and health-related quality of life among women with HIV/AIDS: integrating spirituality into mental health care. Issues Ment Health Nurs. 2006;27(2):185-98.

79. Tangenberg K. Surviving two diseases: addiction, recovery, and spirituality among mothers living with HIV disease. Fam Soc J Contemp Soc Serv. 2001; 82(5):517-24.

\section{Submit your next manuscript to BioMed Central and we will help you at every step:}

- We accept pre-submission inquiries

- Our selector tool helps you to find the most relevant journal

- We provide round the clock customer support

- Convenient online submission

- Thorough peer review

- Inclusion in PubMed and all major indexing services

- Maximum visibility for your research

Submit your manuscript at www.biomedcentral.com/submit
) Biomed Central 